\title{
Pausing As A Prosodic Correlate Of Speech Units In St’át'imcets (LILlOOET SALISH)
}

\author{
Marion Caldecott ${ }^{*}$, Ewa Czaykowska-Higgins ${ }^{\dagger 1}$, Kyra Fortier ${ }^{* 1}$, Karsten Koch ${ }^{\star 3}$, \\ Janet Leonard ${ }^{\# 1}$ and John Lyon ${ }^{2}$ \\ ${ }^{1}$ University of Victoria, Victoria, British Columbia, Canada \\ ${ }^{2}$ California State University, Fresno, California, USA \\ ${ }^{3}$ Alberta Education
}

\section{Introduction}

The reliability of pausing as a correlate to prosodic, syntactic and discourse units has been debated in commonly-studied languages (outlined, for instance, in [1]). Preliminary research in Nxa?amxčín (Interior Salish) [2] has shown that pausing could be a more reliable acoustic correlate of discourse structure than pitch, in line with previous research indicating that Salish languages do not exhibit a strong reliance on pitch to mark information structure [3-6].

The overall goal of this project is to document and analyse intonation patterns in St'át'imcets, to make available and useful the results for language teaching and to compare the results with other Interior Salish languages. The question explored in this study is what role (syntactic, prosodic, narrative) does pausing play in one St'át'imcets narrative [7]? Specifically, the hypotheses tested are:

1) More pauses will occur at clause boundaries than clause internally (following [8] cited in [9])

2) Pauses at narrative and syntactic boundaries will be longer than clause internally, and pauses at larger syntactic and narrative boundaries will be longer than at smaller boundaries (clause internal < clause boundary $<$ sentence boundary < episode boundary) (following [10], [11])

3) There is a relationship between speech rate and pause duration (following [9])

4) There is a relationship between the duration of the preceding prosodic phrase and pause duration (as in [1]).

\section{Method}

\subsection{Participant}

The participant is a 74-year-old fluent speaker of the Tsal'álh dialect, from Nxwísten (Bridge River), Qwa7yán’ak (Carl Alexander).

\subsection{Stimuli \& experimental procedure}

The material is a published 9.5-minute spontaneous narrative recorded in WAV format using a Marantz $\mathrm{P}$ MD660 and Carvin uni-directional microphone ([7]).

The narrative was segmented in ELAN following the syntactic breakdown.

\footnotetext{
*mariongc@uvic.ca

† eczh@uvic.ca

*kyrabw93@gmail.com

- jleonard@uvic.ca

\#karstenak@hotmail.com

> johnlyon@mail.fresnostate.edu
}

38 - Vol. 46 No. 4 (2018)

\subsection{Acoustic Analysis}

The recording was analysed in Praat on a MacBook Pro. Pitch settings were $40-400 \mathrm{~Hz}$ with a silence threshold of 0.1 due to the noisy recording. The recording was segmented into 9 episodes (marked by very long pauses and topic shifts), 19 stanzas (complete sentences) and 55 clauses (the core of a longer sentence that can stand on its own (e.g. minus adjuncts, and non-restrictive relative clauses)).

The duration of pauses longer than $250 \mathrm{~ms}$ was measured (following [9]) and classified for one of four syntactic locations: clause internal, clause boundary, sentence boundary or episode boundary. A subset of stanzas $[12,13,15,16]$ was analysed for a possible relationship between speech rate (syllables/second as measured across the sentence) and pause duration; and between speech duration (number of syllables in the preceding prosodic phrase) and pause duration.

\section{Results}

Of the 55 clauses identified, most exhibited pauses, with only 7 lacking pauses. Hypothesis 1 was supported: the majority of pauses, 47 , or $59.5 \%$, occurred at clause boundaries, while only 32 , or $40.5 \%$, occurred clause internally.

Table 1: Descriptive Data for Pause Duration

\begin{tabular}{lcccc}
\hline $\begin{array}{l}\text { Pause } \\
\text { location }\end{array}$ & $\begin{array}{c}\text { Duration } \\
\text { range }(\mathrm{sec})\end{array}$ & Mean $(\mathrm{sec})$ & Std Dev & $\mathrm{N}$ \\
\hline $\begin{array}{l}\text { Clause } \\
\text { internal }\end{array}$ & $.28-7.9$ & 1.67 & 1.4640214 & 32 \\
\hline $\begin{array}{l}\text { Clause } \\
\text { boundary }\end{array}$ & $.43-6.3$ & 1.73 & 1.3167972 & 28 \\
\hline $\begin{array}{l}\text { Sentence } \\
\text { boundary }\end{array}$ & $.9-3.6$ & 1.92 & 0.8878523 & 11 \\
\hline $\begin{array}{l}\text { Episode } \\
\text { boundary }\end{array}$ & $5.58-33.2$ & 13.31 & 10.223571 & 8 \\
\hline
\end{tabular}

Table 1 shows descriptive statistics for each of the four possible syntactic pause locations. To test hypothesis 2, a one way analysis of variance (ANOVA) was conducted to compare the effect of syntactic location on pause duration. The analysis was significant $(F(3,75)=28.33, p<0.05)$. Descriptively, the mean pause duration was shortest clause internally $(1.67 \mathrm{~s})$ and gradually increased as the syntactic boundary type increased from clause $(1.73 \mathrm{~s})$ to sentence (1.92s) to episode (13.31s). However, Tukey-Kramer pairwise comparisons indicated that hypothesis 2 was only partially supported. Pauses at episode boundaries were significantly longer than at each of the other three pause locations. On the other hand, clause internal pauses, pauses Canadian Acoustics / Acoustique canadienne 
at clause boundaries, and pauses at sentence boundaries were not significantly different from one another (Figure 1).

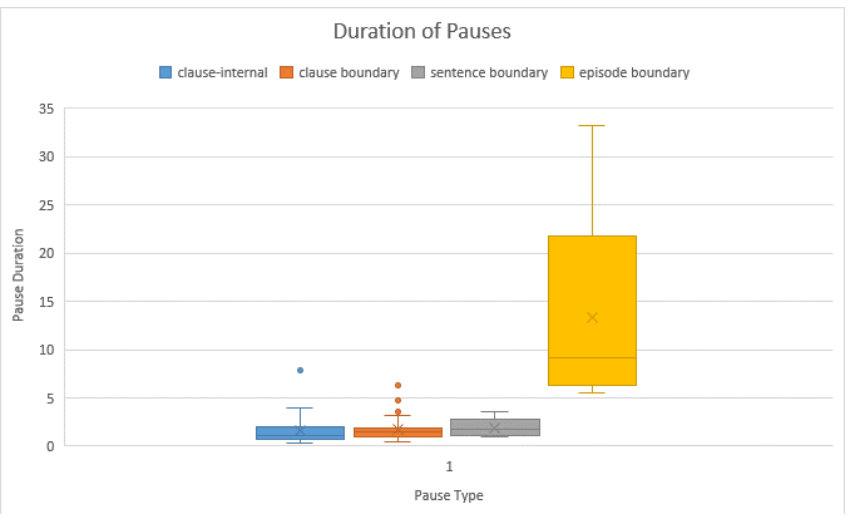

Figure 1: Duration of Pauses by Syntactic Location

To test hypothesis 3, a correlational analysis was conducted on pauses in 4 stanzas, to examine the relationship between speech rate (syllables/second) and pause duration. The analysis was significant $(r(11)=-0.71$, $\mathrm{p}<0.05)$, indicating that as speech rate increased, pause duration decreased.

To test hypothesis 4, a correlational analysis was conducted on pauses in the same 4 stanzas, to examine the relationship between preceding speech duration (number of syllables in the preceding prosodic phrase) and pause duration. The analysis was not significant $(r(11)=-0.19, \mathrm{p}>$ $0.05)$.

\section{Discussion}

These results suggest that St'át'imcets fits into previous research on spontaneous narratives in some respects but not others. Most clauses are marked with pauses (see also [12] on SENĆOFEN). $59.5 \%$ of pauses occur at clause boundaries as compared to $40.5 \%$ clause internally; this finding is similar to the rates of $55 \%$ of pauses at grammatical junctures and $45 \%$ clause internally reported in [8] as cited by [9]. Contrary to the expectation of gradient pause duration, clause internal pauses were NOT found to be significantly shorter than pauses at clause boundaries or sentence boundaries (contra [10]). Only pauses at episode boundaries were significantly longer than pauses at all three other locations. This finding reflects the fact that the narrative analysed was characterized by very long pauses (>5.5 s) to mark major thematic shifts, following [11], [13]. These results, when taken together, suggest that pausing is a more reliable correlate of discourse, not syntax.

In terms of prosodic effects, pause duration was found to be inversely related to speech rate, as for English ([9]), but not affected by the prior phrase length (contra [1]).

However, these correlation analyses were based on only a subset of the data, and warrant further investigation, given the very small number of tokens. Another important limitation of this study to note is that these results are true of one speaker of one dialect and should not be taken as representative of the language as a whole, nor are the results meant to privilege this particular dialect in any way. Future research could consider more speakers of this and other dialects. Preliminary research on a related language shows higher consistency of pausing with clause boundaries, and the higher correlation between pausing and discourse particles in NxaPamxčín [2] vs. phrasal structure suggests that this link between pausing and discourse needs further examination. In terms of the implications for teaching, these results indicate that teachers can direct language students' attention to the function and location of pausing so the student can sound more like elders, a common goal in language revitalization [14].

\section{Acknowledgments}

We would like to thank Qwa7yán'ak for allowing us to use his recording. This research was funded by SSHRC grant 430-2016-00852.

\section{References}

[1] Krivokapić, J. Prosodic planning: Effects of phrasal length and complexity on pause duration. Journal of Phonetics, 35(2), 162179, 2007.

[2] Caldecott, M., and E. Czaykowska-Higgins. Prosodic phrasing in NxaPamxčín (Salish) declarative clauses. Canadian Acoustics, 40(3), 16-17, 2012.

[3] Caldecott, M. St'át'imcets intonation contours: A preliminary study. Canadian Journal of Linguistics/Revue canadienne de linguistique, 61(2), 119-155, 2016.

[4] Davis, H. Two types of discourse configurationality in languages of the Pacific Northwest. Handout presented at the Workshop on the Structure and Constituency of the Languages of the Americas 17, University of Chicago, 2012.

[5] Koch, K. Intonation and focus in Nlhe7kepmxcin (Thompson River Salish). Doctoral dissertation, University of British Columbia, 2008.

[6] Koch, K. A phonetic study of intonation and focus in Nłe?kepmxcin. In Prosodic Categories: Production, Perception and Comprehension, (eds.), Frota, S., Prieto, P. and Elordieta, G., 111144. Dordrecht: Springer, 2011.

[7] Alexander, C., K. Langergraber and J. Lyon. The Flooding of the Upper Bridge River Valley: St'át'imcets Narratives and an Artist's Exhibition. International Conference of Salish and Neighboring Languages 51, 1-17, 2016.

[8] Henderson, A., F. Goldman-Eisler and A. Skarbek. Sequential temporal patterns in spontaneous speech. Language and Speech, 9(4), $207-216,1966$.

[9] Goldman-Eisler, F. Psycholinguistics: Experiments in Spontaneous Speech, Academic Press, London, 1968.

[10] Cooper, W. E., and J. Paccia-Cooper. Syntax and speech (No. 3). Harvard University Press, 1980.

[11] Oliveira, M. Prosodic Features in Spontaneous Narratives. Doctoral Dissertation, Simon Fraser University, 2000.

[12] Benner, A. The prosody of SENĆOFEN. Unpublished course paper, Department of Linguistics, University of Victoria, 2004.

[13] Smith, C. L. Topic transitions and durational prosody in reading aloud: production and modeling. Speech Communication, 42(3-4), 247-270, 2004.

[14] Bird, S. and S. Kell. The role of pronunciation in SENĆOFEN language revitalization. Canadian Modern Language Review, 73(4,) 538-569, 2017. 
Di- Systems for research \& DEVELopment
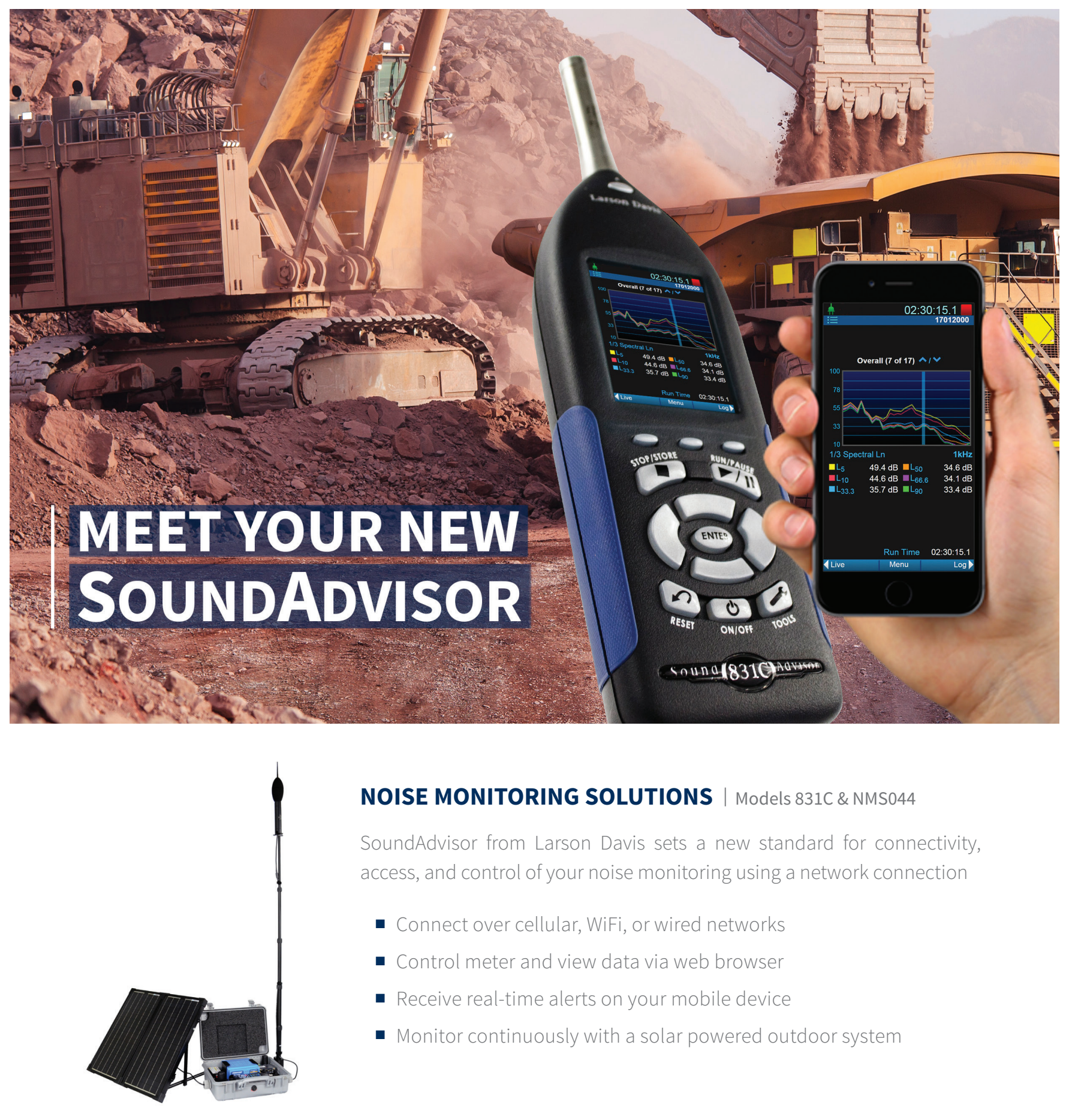

NOISE MONITORING SOLUTIONS | Models 831C \& NMS044

SoundAdvisor from Larson Davis sets a new standard for connectivity, access, and control of your noise monitoring using a network connection

- Connect over cellular, WiFi, or wired networks

- Control meter and view data via web browser

- Receive real-time alerts on your mobile device

- Monitor continuously with a solar powered outdoor system

SoundAdvisor Model NMS044

www.dalimar.ca | info@dalimar.ca | 450.424.0033

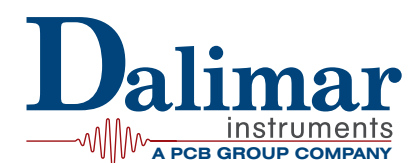




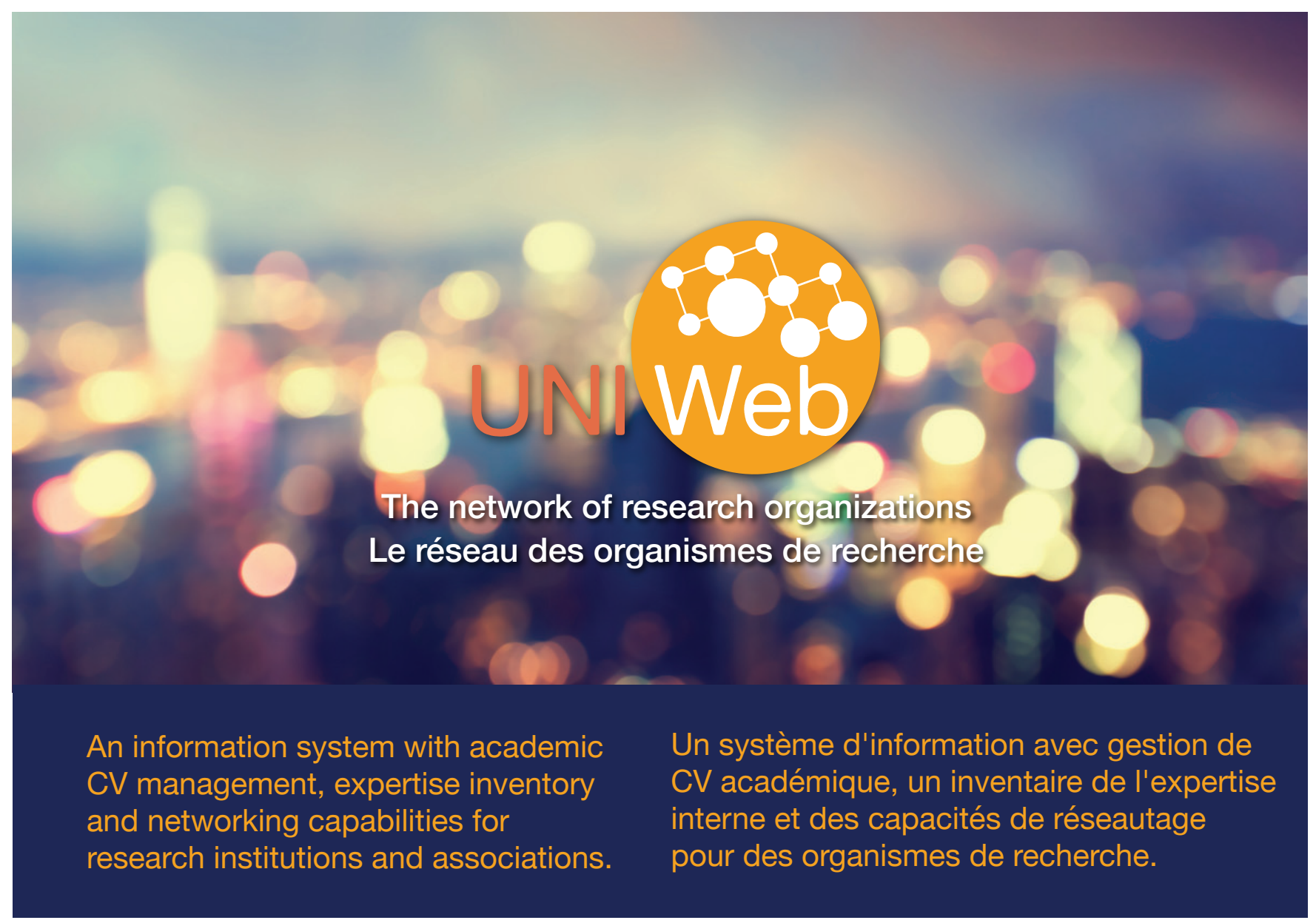

With UNIWeb, researchers can:

\section{Streamline}

funding applications with Canadian

Common CV integration

\section{Reuse}

CCV data to generate academic CVs and progress reports

\section{Mobilize}

knowledge by creating engaging

webpages for research projects

Avec Uniweb, les chercheurs peuvent:

\section{Simplifier}

les demandes de financement grâce à l'intégration au CV commun canadien

\section{Réutiliser}

les données du CVC pour générer des CV académiques et des rapports de progrès

\section{Mobiliser}

les connaissances en créant des pages Web attrayantes pour les projets de recherche

\section{http://uniweb.network}

